\title{
A qualitative study on physical health threatening factors of Iranian seafarers working on ocean going tankers
}

\author{
Fereshteh Baygi ${ }^{1}$, Olaf C. Jensen ${ }^{1 *}$, Ali Asghar Farshad ${ }^{2}$, Farzad Shidfar ${ }^{2}$, \\ Fatemeh Mohammadi-Nasrabadi ${ }^{3 *}$
}

${ }^{1}$ Centre of Maritime Health and Society, Institute of Public Health, University of Southern Denmark, Esbjerg, Denmark

${ }^{2}$ Occupational Health Research Centre, Iran University of Medical Sciences, Tehran, Iran

${ }^{3}$ Department of Food and Nutrition Policy and Planning Research, National Nutrition and Food Technology Research Institute, Faculty of Nutrition Sciences and Food Technology, Shahid Beheshti University of Medical Sciences, Tehran, Iran

*Equally contributed as corresponding author.

\begin{abstract}
Background: Seafaring is a highly physically demanding profession in a risky environment due to exposure to unique job health related risk factors. The purpose of the study is to describe physical health threatening factors of Iranian seafarers working on tankers.

Materials and methods: A qualitative content analysis with inductive approach was performed on 17 Iranian male seafarers in 2016. Subjects were selected by purposive sampling, which continued until data saturation. Data were gathered using semi-structural questionnaire via in-depth-interviews. All interviews were transformed into computer files. Analysis was done based on conventional content analysis approach. Results: Mean job history and age of the participants was $11.9 \pm 7.2$ and $35.8 \pm 9.3$ years, respectively. Two main themes emerged during analysis of data and categories were created. The themes are (1) physical health threatening factors at the ship; (2) high risk ranks at the ship.

Conclusions: The need for addressing nutrition at sea was acknowledged by seafarers. Also, it seems that revision of some regulations regarding seafarers' medical examination, oral health and heart diseases is necessary.
\end{abstract}

(Int Marit Health 2018; 69, 3: 192-200)

Key words: qualitative study, physical health threatening factors, seafarers

\section{INTRODUCTION}

Seafaring is a highly physically demanding profession in a risky environment [1]. Seafarers face tough working conditions when they are on board [2]. Working far from home for several months can lead to some difficulties for their overall health [3]. Their safety and health status are at risk of various factors such as exposure to chemicals and sunlight as well as lifestyle behaviours such as diet and smoking, so that, mentioned subjects are a major concern for companies and themselves as well [4]. In comparison to jobs ashore, seafarers exposed to physical and psychosocial stressors and some specific mental problems [5]. Also hospitalisation and mortality rates among seafarers are higher than their age-matched peers, due to exposure to job-specific health-related risk factors [6]. Being far from home for a long period of time, long working hours, heavy workloads, accidents, maritime disasters, communicable diseases and pirate incident are some of the main stressors, risks and challenges of seafarers on board ships that can cause some consequences for their physical and mental

\footnotetext{
Dr. Olaf Chersten Jensen, Centre of Maritime Health and Society, Institute of Public Health, University of Southern Denmark, Niels Bohrs Vej 9-10. 6700 Esbjerg, Denmark tel: +4565 504260, e-mail: ocj@health.sdu.dk

Dr. Fatemeh Mohammadi-Nasrabadi, No. 7, Hafezi (West arghavan), St., Farahzadi Blvd., Qods Town, Zip code: 1981619573, P.O. Box: 19395-4741, Tehran, Iran, tel: +98-21-22357483, e-mail: f_mohammadinasabadi@sbmu.ac.ir
} 
health [7]. In some quantitative studies physical health of seafarers with focus on cancer and cardiovascular diseases was assessed [8]. Few qualitative studies were done for recognition of health status of sailors and life struggles of their families [4, 9]. In Iran, while seafaring is a crucial occupation, little is known on issues related to their health conditions and workplace difficulties in maritime industry $[3,10]$. So, the object of current study is to describe health threatening factors of Iranian seafarers working on tankers in a qualitative setting. As the first qualitative study in Iranian sailors, the findings have provided some ideas on challenges and problems of tankers for health care providers to boost quality of seafarers' life on board.

\section{MATERIALS AND METHODS}

Content analysis with inductive approach was used for conducting qualitative part of a mix method study on Iranian seafarers working on tankers. This approach is employed when former knowledge about the phenomenon is fragmented or not adequate [11]. Study population included 17 seafarers with different ranks and job degrees of one of the ocean going vessels of National Iranian Tanker Company (NITC). The vessel was sailing on the international rout. All participants had at least 6 months sea service. In order to achieve the maximum diversity of information and to meet research objectives, ship employees were divided into three groups as following:

- deck professionals including: captain, officers and deck sailors;

- engineer workers including: chief engineer, electrician, officers and engine sailors;

- kitchen staff including: chief cook, cooks and waiters.

\section{DATA COLLECTION}

License for the presence of the researcher in the ship was obtained from NITC. Then researcher reviewed work schedule and rest time of each staff members. According to their activities and after informing the master of the vessel, first interviews were planned and done. Before each interview, the researcher assured interviewees that all information would remain confidential, then informed consent was completed by subjects for interviewing and recording. Subjects were selected by purposive sampling, which continued until data saturation. Data were gathered using open-ended semi-structural questionnaire via individual in-depth-interviews in a relaxed environment. The protocol was designed based on objectives of the qualitative study. Also additional questions were used during the interview in order to achieve comprehensive answers to research questions. Additional questions helped the interviewees to be more involved with the research subject. A total of 17 interviews were conducted with 1 masters, 1 chief mate, 1 chief engineer, 2 engineer officer, 2 deck officer, 1 pro- curement officer, 1 chief cook, 1 cooks, 1 waiter, 1 bosun, 2 deck sailor, 1 engine sailor, 1 fitter, 1 electrician. Each interview which lasted 30 to 45 minutes was recorded. After transcription of interviews all of them were transformed into computer files.

\section{DATA ANALYSIS}

Data collection and analysis were done simultaneously. Taking notes for the key points in the field was done at the same time. During the interview, silence, sighs, laughter and postures of all subjects were noticed and wrote by researcher in order to analysis latent content [11]. Data were analysed based on conventional content analysis approach [12]. The content of the recorded interviews were transcribed, managed, coded and interpreted using MAXQDA 2010 software [13]. Data coding was performed in three ways including: open, axial and selective way. Simple and short codes were used in open coding stage at the same time with data gathering. Constant comparison was done in this stage [14]. In the axial coding step, interviews, observations and other sources of data were examined. Also, the researcher compared the experiences and interpretations of different subjects.

\section{DATA TRUSTWORTHINESS}

In this study credibility and conformability of the data were established by maximum variation of sampling and in-depth prolonged engagement in research environment with participants. To confirm dependability, faculty members carried out a second review. Results were also checked by some of the seafarers who did not participate in the research and they confirmed the fitness of the results as well. Research details including procedures, actions and decisions were documented by researcher for other researchers to perform the steps of the research in future studies.

\section{RESULTS}

Table 1 shows the characteristic of studied population. Mean job history and age of the participants was $11.9 \pm$ \pm 7.2 and $35.8 \pm 9.3$ years, respectively. Two main themes emerged during the analysis of data and categories were created, including:

- physical health threatening factors on a ship;

- high risk ranks on a ship. Each is addressed as follows.

\section{PHYSICAL HEALTH THREATENING FACTORS ON A SHIP}

This was the first theme extracted from data and contained two categories including:

\section{Unhealthy eating and inappropriate dietary plan}

Most participants in this study pointed out that unhealthy eating and inappropriate dietary plan which could directly affect seafarers' eating pattern is one of the most 
Table 1. Characteristic of the studied population

\begin{tabular}{llllll}
\hline Position & Number & Educational level & Marital status & Age & Job history [year] \\
\hline Captain & 1 & Master degree & Married & 42 & 17 \\
Chief officer & 1 & Bachelor degree & Married & 37 & 15 \\
Chief engineer & 1 & Bachelor degree & Married & 37 & 15 \\
Engine officer & 2 & Bachelor degree & Single, married & 26,37 & 9,15 \\
Deck officer & 2 & Bachelor degree & Married, single & 35,29 & 12,4 \\
Procurement officer & 1 & Diploma & Married & 35 & 15 \\
Chief cook & 1 & High school & Married & 55 & 24 \\
Cooks & 1 & High school & Married & 44 & 15 \\
Waiter & 1 & Diploma & Single & 25 & 2 \\
Bosun & 1 & High school & Married & 55 & 25 \\
Deck sailor & 2 & High school & Single, married & 25,28 & 2,4 \\
Engine sailor & 1 & High school & Single & 26 & 3 \\
Fitter & 1 & Diploma & Married & 39 & 17 \\
Electrician & 1 & Bachelor degree & Married & 33 & 8 \\
Total & 17 & & & &
\end{tabular}

important health threatening factors. In their opinion unhealthy eating had some reasons that are as follow.

Purchasing freeze provision for the ship. One of the participants remarked: "All foods are frozen and nothing can be done about it. The ship sometime is at the sea for a month and we buy the provision for three months. The foods are mostly frozen and the frozen food loses some vitamins... which I do not know anything about. I do not know what meat is going to lose, but I know that, it is different than fresh food" (second officer).

Another example voiced by chief officer as a barrier to healthy nutrition is inaccessibility to shore which means that during the voyages daily consumption of fruit and vegetables is impossible. "Access to vegetables and fruit is difficult. When the ship is at the port, everything is good, but sometimes it is on a journey for 20 days and we cannot have vegetables and fruits, so we have to use canned and frozen food such as meat that is been frozen for one to two years. The quality of food is not good and it is very low in terms of health. The foods are too greasy or very salty and do not have nutritional value as such. It is very rare that, we get food that is good enough in terms of nutritional value."

Low access to fresh fruit and vegetables due to limited storage time in the refrigerator. Captain of the vessel said that: "The oceangoing ships have shortage of fresh food, as they travel for long distances. Sometimes, it takes 30 to 35 days for the ship to travel from one port to another. If you like to have salad, you cannot as its ingredients can only be stored for 15 to 20 days. When the ship is at the ocean, there is no place for provision. So there is a shortage of vitamins until the time we buy provision. There are meat, chicken, and rice, which can be kept for a long time, but we cannot keep fresh foods that have vitamins."

Purchasing a sizeable amount of provision due to unclear voyage instruction. One of the participants remarked that: "Sometimes, we buy provision for 45 days such as chicken, meat, and so on. But this company is so unorganized that sometimes we have to stay at a port for a couple of months, so we cannot buy a lot of food. If we ran out of food on the ship, (have you seen zombie movies) everybody will be like that. I mean, your dearest friend will become your enemy because of food " (chief cook).

Captains' unwillingness for purchasing provision. As pointed out by most of the participants sometimes captains have sufficient budget and access to shore but their reluctance is a main barrier for purchasing fresh provision. "Some captains are cool and do not buy fresh food even if they have access to. For example, once we did not have fruit when we set sail from Iran; the captain said, he is going to buy some in Fujairah, but he did not buy there. Then we reached the Turkish canal a week later and he did not but any there either. We had to get off the ship in Turkey" (55-year-old bosun).

Another example pointed out by fourth engineer: "If we travel to China, they must buy fruits and vegetables in China. I myself was on a ship, when captain did not buy anything, just imagine, we went without salads and fruits for 2-3 weeks. Another time we went to Turkey, and we should have bought some fruit and vegetables in Egypt, but they ignored it. In the past, we used to go farther away 
such as South Africa, but that time was different. I have seen the captains who were unwilling to buy fresh food, either to save some money for themselves or because of company's policy".

Lack of knowledge regarding healthy eating. Study participants believe that cooks inadequate knowledge was an important barrier to healthy nutrition, as demonstrated by their inability to prepare healthy foods: "Chefs do not know what a healthy diet is and of course do not know how to make healthy food. So, as they do not know or cannot cook healthy food, they increase the amount of oil or salt to make the food tastier. On the ship, it is common for chefs to use lots of oil" (33 year old electrician).

Another participant stated, "I don't think that kitchen personnel have any awareness about healthy foods, they only have experience. But I do not think they know what goes well with what" (second engineer).

Heavy workloads of kitchen staff. Our studied population considered heavy workloads of kitchen staff members to be another barrier to healthy foods. "Kitchen personnel have so much work that they just want to finish their job and go for the rest. They do not care about making healthy food" (35-year-old procurement officer).

Inappropriate food choices. In addition to all mentioned above, participants believe that inappropriate food choices is another factors that can have adverse effects on healthy nutrition. For example, fourth engineer said: "Some captains buy fruit juice instead of fruit. For example, once in China, the captain bought lots of fruit juice with high price instead of fruit and on board of the ship, we had to discard them because they were more like sweet syrup and not like juice. They could buy fresh fruit with much lesser money at that place. I mean, their decisions are wrong".

Meal time interfering with work schedule and rest time. All shift workers in this study stated that their meal time interferes with their working time and this can have some negative effects on their health and work efficiency. For example, the second officer said: "Feeding time is very important. Here is my feeding time when I am at work. For managerial reasons, food is not covered, and I have to eat lunch and then go to work with heavy stomach, and this affects my health and work. They say, it's better to have a rest for half an hour and not have any activity after lunch, but because of our circumstances here, we have to work. In general, people, who are working on shifts, have interrupted feeding time and the rest time".

Facing nutritional problems due to presence of different nationalities. Our subjects believe that differences in nationalities is one of the main challenges for food preferences and can have considerable effects on their eating pattern. For example, a 42-year-old captain stated that: "On a ship, where the personnel are mostly Indian or Pakistani, and only one or two Iranian, of course, the Iranians will have problem with food. Because the Indians eat more vegetarian and spicy food and we eat regular food. Also in the relationship, an Indian is more comfortable with an Indian than an Iranian. So when you we are placed in a group that has different nationality, you are going have $100 \%$ problem nutritionally and mentally".

\section{Physical diseases}

Participants believed that following diseases are the most important physical problems in seafarers.

Skin diseases such as rash, freckle, fungal diseases and cancer. This is common in sailors who have to work under the sun exposure. One of the participants remarked that: "Now the sun is hot and the temperature may be around 70 degrees, so here is a high risk of sunburn. There are some skin funguses that are caused by the intensity of the sun, especially on the side and middle of fingers" (bosun).

Moreover, our subjects stated that skin diseases are a serious health related issue in seafarers because of exposure to chemicals and sunlight. For example, a 42-year-old captain said: "One of the diseases for those who work in the sun is skin diseases such as skin lesions or skin fleas, especially in the warm season. Skin cancer is also very common". Also fourth engineer said: "Diseases of the skin that are caused by contact with chemicals, fuel and oil are too real for us who are working in the engine room".

Oral and dental diseases. One of the participants remarked: "Lack of vitamins causes oral, dental and gum disease. Lime consumption is very good. We are looking for a healthy diet on our ship, but most of the food is frozen here, and the frozen foods cause various diseases" (39-year-old fitter).

Severe headache and migraines. Another example for physical diseases stated by one of the participants is severe headache. The fitter pointed out that: "I often get headache since I became marine personnel, I mean migraine headache. With the little information I have, I think my headache is because of the frozen foods that we eat on the ship".

Gastrointestinal problems such as indigestion, intestinal disorders and constipation. According to participants statements it seems that most intestinal diseases and constipation are associated with lack of fresh foods (such as fruits and vegetables) on board. For example, a 33-year-old electrician said: "Fibre deficiency causes intestinal diseases. It happened to me twice and I developed intestinal diseases (constipation)".

Furthermore, the second officer pointed out that: "Constipation is common on the ship. I, as a medical officer, know this is a common problem. We have at least one or two persons in every voyage that have this problem, and I know this problem is caused by the foods we eat on the ship". 
Respiratory disorders. This category addresses chronic respiratory disorders both in deck and engine staffs. For instance, electrician said: "Pulmonary disease is most common among the personnel of engine room, due to the gases and chemicals used in there. The deck personnel can develop such diseases too, because of the toxic gases and IG". Also, the second officer said: "The cargo gasses cause respiratory problems, which do not show themselves right now, but couple of years later. Older crews often have lung cancer, skin cancer or leukaemia".

Cardiovascular diseases. Some participants claimed heart diseases are more common in seafarers comparing to their peers in offshore jobs. For instance, bosun told that: "Cardiac diseases are also common among the personnel. Heart attack is quite common among them, because they think about their families too much, and they are worried and stressed". Moreover, one of the participants remarked that: "Some diseases are caused by these foods. For example, in the previous trip, I saw someone who was an athlete and did not even smoke, but had a heart attack" (chief cook).

Infertility. In addition to all diseases mentioned above, infertility is another health related problem derived from the data. Chief officer told that: "Alongside the antennas, there is constantly a risk of radio waves. I do not know what disease radio waves are causing as I have not done any study on it. But we have heard that, some radio waves cause cancer and some cause infertility".

Osteoporosis. Findings of current study confirm that in many cases osteoporosis is a problem. So that a 33-year-old electrician stated: "Engine staffs are in the engine room from morning to night. Only after 5 or $6 \mathrm{pm}$, when the sun is not very bright, they can come out, mostly to make phone call. I think all of us have vitamin $D$ deficiency, which is very effective in osteoporosis, so I try to use the pill to prevent it".

Varicose. According to the participants, most of the seafarers suffer from varicose veins of the legs. One of the participants remarked: "Varieties of varicose veins are common among mariners, because we are always on our feet" (second officer).

Rupture of the disc and arthritis of the joints. Most seafarers participating in this study pointed out that they have seen disk abnormalities and arthritis in a couple of their colleagues. For example, one of the participants said: "Most sailors have either foot pain or back pain. I now have ruptured back disc, because our work require us to stand on our feet. Here, tables are everywhere, so we have to stand on our feet" (first cook).

Also, fourth engineer said: "The problem that most of the personnel in the engine room have and I am also dealing with is the slight dislocation of C5, C6 spinal cord discs. The arthritis of the neck and knees are also very common among engine room personnel".
Fatty liver. Another health threatening issue among seafarers is fatty liver. So that the second officer said: "The prevalence of fatty liver has increased among my colleagues, which in my opinion it has increased in the whole of Iran. I do not know what is good or bad for fatty liver. I know main things like alcohol and egg... but I do not know any more. Maybe the diet has an effect on it".

Obesity, high blood pressure and hyperlipidaemia. Data analysis revealed the prominent role of unhealthy dietary plan and sedentary lifestyle in the development of non-communicable diseases such as obesity, high blood pressure and hyperlipidaemia. Chief officer told that: "Not having fruit and vegetables may not affect us in the short term, but it will certainly affect us in the long term. Now, many of my colleagues on my age are obese or have high blood cholesterol and pressure. You see, these situations are more often among officers, because they don't have much physical activity".

\section{HIGH RISK RANKS AT THE SHIP}

This theme addressed individuals who encounter more threatening conditions at the ship and two categories of this theme are as follow:

\section{Engineers}

Participants believe that engine staffs are more likely to be at risk due to variety of reasons. Following hazards, injuries and health problems were mentioned.

Cardiovascular diseases like stroke. Findings of the current study confirm that working in high temperature environment along with other risk factors can cause cardiovascular diseases especially in engine staffs. The captain stated that: "Sometimes there is a heart problem that no one on the ships can do anything about. We have had even death due to heart attack or stroke in engine staff members who have to work in high temperature".

Visual disorders and deafness. According to participants, eyes and hearing abnormalities are common in engine workers too. "The engine room personnel endure loud noises and become deaf, and as they never see the sun, they face vision abnormalities too. We wear sunglasses when the sun is too strong, but the sunglasses are not standard and they weaken our vision. They even make people blind. In general, problem with eyesight, hearing and skin are common in our profession" (55-year-old bosun).

Infertility. Participants mentioned infertility is a problem in seafarers especially in engine staffs. "I'm going to tell you that, the engine room personnel have infertility problem because of working at the high temperature of the engine room" (engineer).

Osteoporosis. Osteoporosis was a common concern among engine staff. They believed that the risk of vitamin $D$ deficiency along with other bone related abnormalities is 
high in all engine room workers. A 33-year-old electrician stated that "The engine room personnel also have vitamin $D$ deficiency, because they do not come on the deck and do not get sunshine".

Work-related injuries and fractures. In addition, engine personnel are more likely to be at risk due to some work-related injuries. The second engineer said: "The dangers of our work, which I have not been involved in myself, include: sliding, falling, burning, heating objects and bone fractures. Sometime, there is an emergency and the work has to go ahead and you have no choice but to comply. In these situations, there is lots of work pressure and tiredness could make you slide and fall down when going up and down the stairs".

\section{Captain and key officers}

From participants' standpoint, key personnel encounter following problems more than other staff members.

Facing too much stress. As pointed out by most participants, heavy workload of captains was an important stressor that can have numerous adverse effects on their mental health. One of the participants remarked that: "As a chef, the only stress that I have is to make a good meal and feed everyone. But someone like the captain has many stresses. If someone gets a headache, he is under stress about what should be done, or what should be done if the ship hits something" (chief cook).

Loneliness. Our studied population believed that since high rank staffs especially captains have to limit their social relationship, they are more likely to be at risk of psychological problems due to loneliness. "Our rank limits our relationships with the lower ranking personnel. For example, as a captain, I cannot talk casually with a sailor and laugh, because everything has a discipline. Well, sometime I say hello to a sailor and pad him on shoulder but that is all. Since you are a manager, you cannot get too close with the personnel" (42-year-old captain).

Sleep disorders. Participants' statements suggest existence of sleep disorders as a result of facing too much stress in key personnel especially masters. "I think the higher your rank gets, the situation gets harder. It gets easier physically, but emotionally you get much more sleepless nights and stress. Sometimes in my dream, I make plan for tomorrow. My brain is awake, but my body is asleep. When I was a lower ranking officer, I had less stress because I had less working pressure and shorter working time" (captain).

\section{DISCUSSION}

The purpose of the current study was to explore job related risks and challenges as experienced by seafarers participating in the study. In our subjects' point of view, the most prominent health threatening factor at the ship was unhealthy eating and inappropriate dietary plan which could directly affect their eating pattern and overall health.

Our studied population believe that, due to using poor quality provision and lack of knowledge regarding healthy eating, most cooks prepare fatty and salty meals at the ship. Also, in long voyages there is low access to fresh fruit and vegetables. They think since they do not follow a healthy diet during their missions, heart attacks and strokes occur on board. Previous studies revealed that cardiovascular disease is one of the main causes of death among seamen on British and Danish merchant ships [15, 16]. Researchers pointed out that the most important practical measures available to decrease cardiovascular disease risk among seafarers is training cooks in low fat diets [17]. In contrast with our study, Kum and Bosnak [18] showed that Turkish seafarers pay attention to the healthiness of their food and drink. Also their results demonstrated that Turkish seafarers try their best to stay away from harmful food and drink, as much as possible. According to their results, $38.3 \%$ of subjects declared that they eat fast foods once a week, $8.3 \%$ of them 2-3 times a week, $6.7 \%$ of them 4-5 times a week, $26.7 \%$ once a month, $10 \%$ once in 2 months.

In our study, subjects believe that skin and lung cancer are more common physical diseases in seafarers. They think since ships transport petroleum products and other kinds of toxic cargos, during tank cleaning, loading and unloading high benzene concentrations can have adverse effects on their health. So that, most of them will face different kind of cancers in the future. Oldenburg et al. [19] in his study showed that the causes of the elevated risks of some cancers among seafarers are not clear, although some of the lifestyle related factors - smoking, diet and alcohol for instance - play a causative role in this regard. Furthermore, exposure to UV-light from the sun should be considered as one of the main risk factors for skin cancer [19]. Other studies revealed that in engine officers and ratings the incidence for lung cancer was more than twice as high as expected [20]. Researchers recommended that bio-monitoring examination for toxic substances in order to detect hazardous exposure at an early stage should be repeated in seafarers' medical tests on a regular basis [19].

Studied population remarked that seafarers are more likely to be at risk of oral and dental issues due to limited access to vitamins of fresh foods. Also, they believe that absence of professional dental help can cause suffering to the seafarers with dental emergencies and may impede the ones' duty. The US submarine reported 90 medical requests for dental issues between 1991 and 1999. From 5187 consultations at submarines only $3 \%$ had dental issues. $26.5 \%$ of mariners were dentally fit whereas $67.3 \%$ of them needed dental treatment within next 12 months. Also it was found that dental emergency incidence rate is 
5.0 per 100,000 person-days at sea [21] while in the other study researchers revealed that emergency incidence rate for cruise-ship crews was 48.3 per 100,000 person-days at sea [22]. Dahl [23] in his study pointed out that pre-boarding medical examinations were up to the expected standards but in order to boosting the quality of seafarers' medical tests, dental professional input should be included in new revision of International Labour Organisation/Word Health Organisation standards.

Our results revealed that severe headache and migraines are common issues in seafarers. Seafaring is associated with special mental, physical and psychological stressors [19]. In a review study, researcher showed that $50 \%$ to $80 \%$ of patients report stress as a precipitating factor for migraine headaches. Researchers believe that acute stress can cause biological modifications so that the threshold of ones' susceptibility to migraine attack decreases [24]. Also a cross-sectional study on Iranian subjects revealed that there is an association between gastrointestinal disorders and migraine [25]. Since our studied population mentioned that gastrointestinal problems like constipation and indigestion are common in seafarers, maybe mentioned issues are one of the effective factors for starting severe headaches.

We found that respiratory disorders is one of the common physical diseases especially in engine staff. Novalbos et al. [26] in the study conducted on Andalusian fishery sector revealed that the main problems reported by fishermen were musculoskeletal disorders, respiratory diseases, eye problems and digestive system abnormalities. A high level of smoking and alcohol intake was observed so that $60 \%$ of those surveyed smoked.

Studied subjects pointed out that infertility is another physical abnormality in some of their colleagues due to exposure to chemicals, radiation and working in high temperature environment. In industrialized countries the infertility has increased from $8 \%$ to $15 \%$ during last two decades. The effects of radiation on reproduction have been known since 1920. Also, toxic chemicals, intense heat, radiation has recognized as occupational hazards on reproductive system [27].

Osteoporosis - most common chronic metabolic bone disease - is a silent disease which causes secondary health problems and even death and it is seen in all age groups [28]. One in 5 men in general population will experience osteoporotic fractures in their lifetime according to recent statistics from the International Osteoporosis Foundation [29]. Our studied population remarked that osteoporosis is a health issue in engine staff members due to following inappropriate dietary plan such as lack of vitamin $D$ intake. Also they pointed out that, since they work long hours in a dark engine room, they are deprived of sunlight as a main source of vitamin D. Therefore, osteoporosis and its fractures will occur for them in near future - as it was seen in their colleagues. Other studies revealed that intensive physical activity with low calcium intake can cause additional stress on the skeleton. Heavy sweating and insufficient calcium intake can lead to diminished bone reservoir under the influence of elevated levels of PTH [30, 31]; therefore, engine staffs are more likely to be at risk of osteoporosis in becoming years.

Our studied population mentioned that most of the seafarers working on deck and in the kitchen suffer from varicose veins of the legs. In the study conducted by Hansen et al. [32], the findings revealed that due to long hours of standing on the mobile deck varicose veins of the legs are prevalent in the fishermen. Whereas, in merchant ships mentioned health problem is considerably less so that no excess risk was observed in this study. Also in another study, prolonged standing at work has been shown to be a risk factor for the occurrence of varicose veins [33].

In current study, subjects believe that the prevalence of fatty liver has increased among their colleagues. Our quantitative study conducted on Iranian seafarers in 2014 revealed that the prevalence of elevated aspartate aminotransferase and alanine aminotransferase were $5.9 \%$ and $21.3 \%$, respectively [34]. Recent evidences indicate that non-alcoholic fatty liver disease is the main common reason of liver diseases in Iran [35]. High rates of alcohol-related diseases in seamen have been reported in other countries as well so that it is recommended mentioned problem should be a priority for preventive actions in maritime industry [36, 37].

Obesity, high blood pressure and hyperlipidaemia are common problems among our subjects, based on their opinion. The study conducted in 2015 showed that the prevalence of obesity and abdominal obesity among Iranian seafarers were $8.6 \%$ and $38.5 \%$, respectively [10]. Also, the prevalence of high blood pressure was $23.7 \%$ in Iranian sailors [34]. Published data show that the prevalence of high blood pressure significantly increased from $14.8 \%$ to 42.1\% from 1990 to 2000 among seafarers [38]. In comparison with other occupations, seafarers live and work in special conditions which can lead suffering from some specific diseases [10].

Based on our knowledge, the main strength of the study is the fact that, this is the first qualitative study which assessed health threatening factors of Iranian seafarers working on tankers. Moreover, presenting the researcher at the ship and living with sailors through the period of the study provided a deep understanding of living and working conditions at sea. The limitations of the study are open ending questions and excessive interpretation of the researcher that can be a threat to successful content analysis. However, this applies to all qualitative methods of analysis. 


\section{CONCLUSIONS}

Results from this study have indicated physical health threatening factors of Iranian seafarers. Furthermore our findings pointed out high risk ranks who encounter more threatening conditions at the ship. It is suggested that the International Maritime Organisation and other leading associations in maritime industry should be more sensitive regarding nutrition at sea. Also revision of guidelines and regulations relevant to annual medical examination of seafarers in some fields such as oral health and heart diseases is necessary.

\section{ETHICS APPROVAL AND CONSENT TO PARTICIPATE}

This study was proposed and approved by the Ethics-in-Research Commission of Iran University of Medical Sciences. Also Informed consent was obtained from all individual participants included in the study.

\section{ACKNOWLEDGEMENTS}

The source of data used was derived from the PhD thesis of Dr. Fereshteh Baygi. The authors wish to thank the manager and participants of National Iranian Tanker Company for their great contribution.

\section{FUNDING}

This study was funded by Iran University of Medical Sciences (grant no. 25800).

\section{COMPETING INTERESTS}

The authors declare that they have no competing interests.

\section{REFERENCES}

1. IMHA. International Maritime Health Association. Newsletter January. 2012: 14.

2. Hjarnoe L, Leppin A. Health promotion in the Danish maritime setting: challenges and possibilities for changing lifestyle behavior and health among seafarers. BMC Public Health. 2013; 13: 1165 , doi: $10.1186 / 1471-2458-13-1165$, indexed in Pubmed: 24330425.

3. Baygi F, Jensen OC, Mohammadi-Nasrabadi F, et al. Factors affecting health-promoting lifestyle profile in Iranian male seafarers working on tankers. Int Marit Health. 2017; 68(1): 1-6, doi: 10.5603/ IMH.2017.0001, indexed in Pubmed: 28357829.

4. Jensen OC, Sørensen JFL, Thomas M, et al. Working conditions in international seafaring. Occup Med (Lond). 2006; 56(6): 393-397, doi:10.1093/occmed/kql038, indexed in Pubmed: 16804089.

5. Carotenuto A, Molino I, Fasanaro AM, et al. Psychological stress in seafarers: a review. Int Marit Health. 2012; 63(4): 188-194, indexed in Pubmed:24595974.

6. Andruskienè J, Barsevičienè Š, Varoneckas G. Poor sleep, anxiety, depression and other occupational health risks in seafaring population. TransNav, the International Journal on Marine Navigation and Safety of Sea Transportation. 2016; 10(1): 19-26, doi: 10.12716/1001.10.01.01.
7. Slišković A, Penezić Z. Occupational stressors, risks and health in the seafaring population. Review of Psychology. 2016; 22(1-2): 29-39, doi:10.21465/rp0022.0004.

8. Kaerlev L, Hansen J, Hansen HL, et al. Cancer incidence among Danish seafarers: a population based cohort study. Occup Environ Med. 2005; 62(11): 761-765, doi: 10.1136/oem.2005.020818, indexed in Pubmed: 16234401.

9. Yur TN. qualitative study on life struggles of the wives of the seafarers. J Marit Res. 2012; IX(2): 7-12.

10. Baygi F, Jensen OC, Qorbani M, et al. Prevalence and associated factors of cardio-metabolic risk factors in Iranian seafarers. Int Marit Health. 2016; 67(2): 59-65, doi: 10.5603/IMH.2016.0013, indexed in Pubmed: 27364169.

11. Elo S, Kyngäs $\mathrm{H}$. The qualitative content analysis process. J Adv Nurs. 2008; 62(1): 107-115, doi: 10.1111/j.1365-2648.2007.04569.x, indexed in Pubmed: 18352969.

12. Hsieh HF, Shannon SE. Three approaches to qualitative content analysis. Qual Health Res. 2005; 15(9): 1277-1288, doi: 10.1177/1049732305276687, indexed in Pubmed: 16204405.

13. Silver C, Lewins A. Using software in qualitative research: a step-by -step guide. Sage. 2014, doi: 10.4135/9781473906907.

14. Corbin J, Strauss A. Basics of qualitative research (3rd ed.): techniques and procedures for developing grounded theory. Sage. 2008, doi:10.4135/9781452230153.

15. Roberts SE, Hansen HL. An analysis of the causes of mortality among seafarers in the British merchant fleet (1986-1995) and recommendations for their reduction. Occup Med (Lond). 2002; 52(4): 195-202, indexed in Pubmed: 12091585.

16. Hansen HL. Surveillance of deaths on board Danish merchant ships, 1986-93: implications for prevention. Occup Environ Med. 1996; 53(4): 269-275, indexed in Pubmed: 8664966.

17. Oldenburg M, Jensen HJ, Latza U, et al. Coronary risks among seafarers aboard German-flagged ships. Int Arch Occup Environ Health. 2008; 81(6): 735-741, doi: 10.1007/s00420-007-0261-5, indexed in Pubmed: 17909838.

18. Kum S, Boşnak T. A qualitative study on nutrition of turkish seafarers. J ETA Maritime Science. 2016; 4(2): 135-147, doi: 10.5505/ jems.2016.20591.

19. Oldenburg M, Baur X, Schlaich C. Occupational risks and challenges of seafaring. J Occup Health. 2010; 52(5): 249-256, indexed in Pubmed:20661002.

20. Forsell K, Hageberg S, Nilsson R. Lung cancer and mesothelioma among engine room crew-case reports with risk assessment of previous and ongoing exposure to carcinogens. Int Marit Health. 2007; 58(1-4): 5-13, indexed in Pubmed: 18350972.

21. Deutsch WM. Dental events during periods of isolation in the U.S. submarine force. Mil Med. 2008; 173(1 Suppl): 29-37, indexed in Pubmed: 18277720.

22. Sobotta BAJ, John MT, Nitschke I. Dental practice during a world cruise: treatment needs and demands of crew. Int Marit Health. 2007; 58(1-4): 59-69, indexed in Pubmed: 18350976.

23. Dahl E. Crew referrals to dentists and medical specialist ashore: a descriptive study of practice on three passenger vessels during one year. Int Marit Health. 2006; 57(1-4): 127-135, indexed in Pubmed: 17312701.

24. Radat F. Stress et migraine. Revue Neurologique. 2013; 169(5): 406-412, doi: 10.1016/j.neurol.2012.11.008.

25. Martami F, Ghorbani Z, Abolhasani M, et al. Comorbidity of gastrointestinal disorders, migraine, and tension-type headache: a cross-sectional study in Iran. Neurol Sci. 2018; 39(1): 63-70, doi: 10.1007/ s10072-017-3141-0, indexed in Pubmed: 29022143. 
26. Novalbos J, Nogueroles P, Soriguer M, et al. Occupational health in the Andalusian Fisheries Sector. Occup Med (Lond). 2008; 58(2): 141-143, doi:10.1093/occmed/kqm156, indexed in Pubmed: 18245787.

27. Kumar S. Occupational Exposure Associated with Reproductive Dysfunction. J Occup Health. 2004; 46(1): 1-19, doi: 10.1539/joh.46.1.

28. Cosman F, de Beur SJ, LeBoff MS, et al. National Osteoporosis Foundation. Clinician's Guide to Prevention and Treatment of Osteoporosis. Osteoporos Int. 2014; 25(10): 2359-2381, doi: 10.1007/ s00198-014-2794-2, indexed in Pubmed: 25182228.

29. Wright NC, Looker AC, Saag KG, et al. The recent prevalence of osteoporosis and low bone mass in the United States based on bone mineral density at the femoral neck or lumbar spine. J Bone Miner Res. 2014; 29(11): 2520-2526, doi: 10.1002/jbmr.2269, indexed in Pubmed: 24771492.

30. Guillemant J, Accarie C, Peres G, et al. Acute effects of an oral calcium load on markers of bone metabolism during endurance cycling exercise in male athletes. Calcif Tissue Int. 2004; 74(5): 407-414, doi: 10.1007/s00223-003-0070-0, indexed in Pubmed: 14735261.

31. Lappe J, Cullen D, Haynatzki G, et al. Calcium and vitamin d supplementation decreases incidence of stress fractures in female navy recruits. J Bone Miner Res. 2008; 23(5): 741-749, doi: 10.1359/ jbmr.080102, indexed in Pubmed: 18433305.
32. Hansen HL, Tüchsen F, Hannerz H. Hospitalisations among seafarers on merchant ships. Occup Environ Med. 2005; 62(3): 145-150, doi:10.1136/oem.2004.014779, indexed in Pubmed: 15723878.

33. Tüchsen F, Krause N, Hannerz $\mathrm{H}$, et al. Standing at work and varicose veins. Scand J Work Environ Health. 2000; 26(5): 414-420, doi:10.5271/sjweh.562.

34. Baygi F, Jensen OC, Qorbani M, et al. Pattern of some risk factors of cardiovascular diseases and liver enzymes among Iranian seafarers. Med J Islam Repub Iran. 2017; 31: 23, doi: 10.18869/mjiri.31.23, indexed in Pubmed: 29445652.

35. Jamali R, Khonsari M, Merat S, et al. Persistent alanine aminotransferase elevation among the general Iranian population: prevalence and causes. World J Gastroenterol. 2008; 14(18): 2867-2871, indexed in Pubmed: 18473412.

36. Coggon D, Harris EC, Brown T, et al. Occupation and mortality related to alcohol, drugs and sexual habits. Occup Med (Lond). 2010; 60(5): 348-353, doi:10.1093/occmed/kqq040, indexed in Pubmed: 20407041.

37. Hemmingsson T, Lundberg I, Nilsson R, et al. Health-related selection to seafaring occupations and its effects on morbidity and mortality. Am J Ind Med. 1997; 31(5): 662-668, indexed in Pubmed: 9099372.

38. Pougnet R, Pougnet L, Loddé BL, et al. Cardiovascular risk factors in seamen and fishermen: review of literature. Int Marit Health. 2013; 64(3): 107-113, indexed in Pubmed: 24072535. 